\title{
Erratum to: Do sophisticated investors use the information provided by the fair value of cash flow hedges?
}

\author{
John L. Campbell ${ }^{1} \cdot$ Jimmy F. Downes $^{2}$ • \\ William C. Schwartz Jr. ${ }^{3}$
}

\section{Erratum to: Rev Account Stud (2015) 20:934-975 DOI 10.1007/s11142-015-9318-y}

Appendix 1 has been erroneously published in the original article, which is corrected with this erratum.

\section{Appendix 1: Illustration of the implications of cash flow hedge gains/ losses for future profitability}

This appendix illustrates how cash flow hedge gains/losses provide a signal about future profitability after the hedge has been reclassified into earnings and the firm is fully exposed to the underlying price movements that created the gain or loss.

The online version of the original article can be found under doi:10.1007/s11142-015-9318-y.

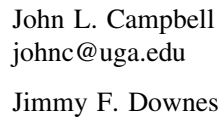

1 J.M. Tull School of Accounting, Terry College of Business, University of Georgia, Athens, GA 30602-6252, USA

2 School of Accountancy, College of Business Administration, University of Nebraska-Lincoln, Lincoln, NE 68588-0488, USA

3 Department of Accounting, Spears College of Business, Oklahoma State University, Stillwater, OK 74078-4011, USA 
Suppose a firm has revenue of $\$ 4$ and cost of goods sold (COGS) of $\$ 2$. Revenue is constant over the next few years. The firm sells only one product. And taxes are ignored. During year $t$, the firm hedges its year $t+1$ inventory costs. After the hedge is in place and the current year's inventory has been purchased, the price of inventory rises by $\$ 1$, from $\$ 2$ to $\$ 3$. Therefore, in year $t$, the firm has a hedge gain of $\$ 1$ in AOCI. However, because the firm had purchased its inventory at $\$ 2$, COGS would be $\$ 2$ in year $t$.

In year $t+1$, the firm benefits from the hedge. It purchases inventory at the "new" price of $\$ 3$ but has the offsetting hedge gain of $\$ 1$ being reclassified into the income statement. Thus, COGS would again be $\$ 2$.

However, after year $t+1$, there is no hedge, so COGS is $\$ 3$ in years $t+2$ and $t+3$. Therefore, income is $\$ 2$ in $t$ and $t+1$ but $\$ 1$ in years $t+2$ and $t+3$. $^{1}$ This scenario is illustrated graphically and through journal entries below:

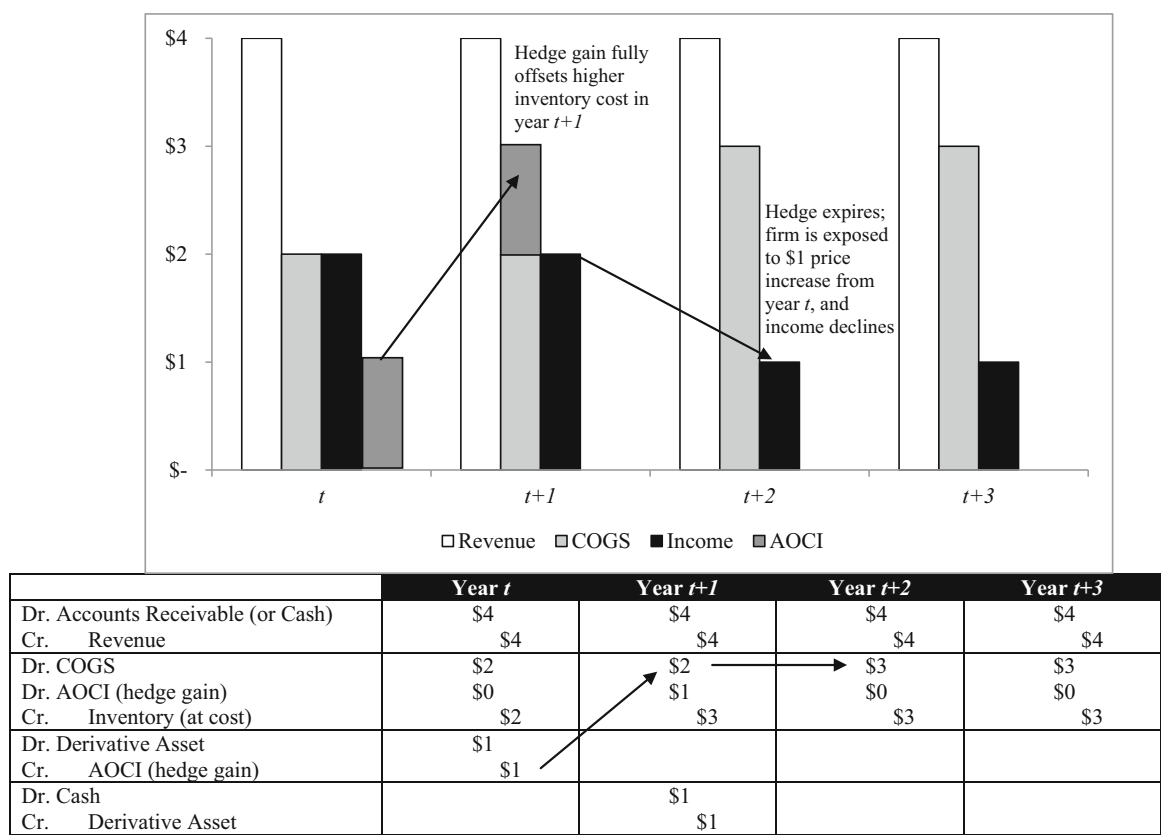

\footnotetext{
1 This illustration assumes that inventory costs follow a random walk (and stay at $\$ 3$ for the foreseeable future) that the firm only hedges in year $t$ and that it only hedges for the next year. We test the random walk and 1-year-horizon assumptions in Sect. 2. Furthermore, as explained in Sect. 2, even if the firm enters into hedges in year $t+1$, these hedges will lock the firm into a $\$ 3$ cost for its inventory and thus only protect the firm from additional cost increases beyond those experienced in year $t$.
} 